\title{
CONSCIÊNCIA, MATÉRIA E VIDA: ALGUMAS CONSIDERAÇÕES SOBRE A METAFÍSICA DA NATUREZA EM BERGSON
}

\author{
Silene Torres Marques \\ Universidade Federal de São Carlos
}

Resumo: Nosso objetivo é apresentar algumas considerações sobre a filosofia da natureza em Bergson, sobretudo, indicar como sua obra é a expressão de um esforço para articular seus diversos aspectos, ou seja, consciência, matéria e vida. Enfim, mostrar que essa articulação somente é possível por intermédio de uma ontologia da duração.

Palavras-chave: Duração; Consciência; Vida; Matéria; Natureza.

\begin{abstract}
Our aim is to present some considerations about the philosophy of nature in Bergson, above all, to indicate how his work is the expression of an effort to articulate his various aspects, that is, consciousness, matter and life. Finally, to show that this articulation is only possible through an ontology of duration.
\end{abstract}

Keywords: Duration; Consciousness; Life; Matter; Nature.

Como é sabido, o início da filosofia de Bergson é marcado pela famosa tese sobre a duração psicológica exposta em seu livro Ensaio sobre os dados imediatos da consciência (1889). Todavia, o que pouco se sabe é que esse início foi impulsionado por um estudo das 'ciências da natureza'. Em carta a William James, de maio de 1908, ele relata ao filósofo americano que, influenciado pelo evolucionismo de Herbert Spencer, sua intenção, nos anos seguintes (1881 a 1883) à sua saída da École Normale, era consagrar-se à 'filosofia das ciências'; nesse sentido, empreendeu o estudo de 'algumas noções científicas fundamentais'. Ao analisar o modo como a noção de tempo era abordada na mecânica ou na física se surpreendeu: 'Percebi, para meu grande espanto, que o tempo científico não dura, que não mudaria nada em nosso conhecimento científico das coisas se a totalidade do real se desenvolvesse de um golpe no instantâneo, e que a ciência positiva consiste essencialmente na eliminação da duração' (BERGSON, 1972, p.766). Essa constatação causa uma reviravolta em suas ideias, tornando-se o ponto de partida de 'uma série de reflexões' que pouco a pouco levaram-no a rejeitar 'quase tudo que havia 
aceitado até então', e a mudar completamente seu ponto de vista sobre o tempo e o movimento.

É dessa orientação inicial que surgem suas primeiras análises sobre o tempo da consciência, tema central de seu primeiro livro. Citemos a famosa definição da duração, presente no segundo capítulo do livro: 'A duração pura é a forma que adquire a sucessão de nossos estados de consciência quando nosso eu se deixa viver, quando ele se abstém de estabelecer uma separação entre o estado presente e os estados anteriores' (BERGSON, 2007, p.74-75). Justamente, no segundo e terceiro capítulos Bergson resume algumas considerações sobre o tempo da ciência que outrora pesquisara, agora contraposto a essa nova concepção de tempo, que é o tempo da consciência: o tempo medido pela ciência possui um caráter relativo, diferentemente do tempo da consciência, que é um tempo vivido e possui um sentido absoluto. A ciência opera sobre o tempo e o movimento excluindo deles a essência, ou seja, do movimento a mobilidade e do tempo a duração: o intervalo de duração não conta. Por isso, se todos os movimentos do universo se produzissem duas ou três vezes mais rápido, não haveria mudança em suas fórmulas e números, diferentemente da consciência, que experimentaria uma mudança qualitativa e indefinível (BERGSON, 2007, p.87). Essa situação é comparada à de um astrônomo que prevê um eclipse: 'ele reduz infinitamente os intervalos de duração, os quais não contam para a ciência, e percebe assim em um tempo muito cuto - alguns segundos, no máximo - uma sucessão de simultaneidades que ocupará vários séculos para a consciência concreta, obrigada a viver seus intervalos' (BERGSON, 2007, p.87). A consciência vive a duração, que é o próprio intervalo, e este não interessa à ciência, mas à psicologia. Ela não percebe o tempo como uma soma de 'unidades de duração' e não faz sua medição, no entanto, um sentimento por ela experimentado que 'durasse duas vezes menos dias, por exemplo, não seria para ela o mesmo sentimento; faltaria a esse estado de consciência uma multidão de impressões que vieram enriquecê-lo e modificar-lhe a natureza' (BERGSON, 2007, p.147). Bergson reitera em vários momentos desses capítulos o fato de que os estados de consciência duram, por isso são progressos e não coisas e que sua essência é mudar incessantemente; suprimir quaisquer de seus momentos seria empobrecê-los, seria modificar sua natureza e qualidade, enfim, seria empobrecer o conjunto de uma história (BERGSON, 2007, p.147-148). Assim, a duração da consciência implica a sucessão contínua de estados que se penetram, mas essa sucessão é na verdade uma organização dinâmica e qualitativa que liga passado e presente, e esses estados são estados heterogêneos que no entanto se penetram por serem solidários. Trata-se de uma multiplicidade de elementos qualitativamente diferentes, moventes, e que 
se desenvolvem numa continuidade indivisível, como uma totalidade. $\mathrm{O}$ ato verdadeiramente livre será justamente a expressão dessa totalidade heterogênea e diferenciada.

Essa concepção do tempo como duração determinou a filosofia de Bergson $^{1}$, e desde o início fez com que ele a considerasse uma alternativa ao evolucionismo spenceriano. Mais do que isso, ela será o dado fundamental a partir do qual Bergson elabora uma ontologia, base de sua filosofia da natureza. Seus três primeiros livros representam o esforço para dar conta de cada uma das dimensões da natureza, ou seja, consciência, matéria e vida. Em conjunto, eles configuram a tentativa de realização de uma metafísica que busca reunir essas três dimensões e procura dar conta da complexidade de suas relações. A evolução criadora (1907), seu terceiro livro, expressa a maturidade dessa ontologia e de seu método, de modo que tudo se passa como se esse livro, considerado por muitos o ápice de sua filosofia, fosse o resultado de um projeto iniciado no Ensaio com a consideração da duração da consciência. Não nos surpreende, nesse sentido, sua afirmação, já na introdução, de que as posições sobre o problema da vida serão as mesmas que havia emitido em seu primeiro livro sobre a consiência: No presente trabalho, aplicamos essas mesmas ideias à vida em geral, considerada ela própria do ponto de vista psicológico' (BERGSON, 2005, p.XV).

Ora, a despeito dessa estreita relação entre os dois livros (Ensaio e $A$ evolução criadora), para o que nos interessa, ou seja, mostrar como a investigação da natureza em Bergson implica a articulação complexa entre consciência, matéria e vida, e o significado metafísico dessa articulação, é preciso dar alguns passos: primeiramente, considerar alguns aspectos do estudo desenvolvido em seu livro intermediário, Matéria e memória (1896); depois, destacar o contexto científico no qual nosso autor lança as bases de sua metafísica, no limiar do século XX.

A investigação levada a cabo em Matéria e memória é central: articulando teses de teoria do conhecimento, psicologia e metafísica, esse segundo livro de Bergson já esboça um pensamento sobre a natureza na medida em que sua reflexão procura dar conta das complexas relações entre corpo e consciência, matéria e memória: o dualismo do Ensaio é atenuado e seus termos aparecem cada vez mais articulados. Desde o início a consciência é

1 Na famosa carta a Höffding, de 15 de março de 1915, ele enfatiza: 'Na minha opinião, todo resumo de minhas visões as deformará em seu conjunto e as exporá, por isso mesmo, a um grande número de objeções, se ele não se coloca de início e não retorna incessantemente ao que considero o centro de minha doutrina: a intuição da duração. A representação de uma multiplicidade de 'penetração recíproca', (...) heterogênea, qualitativa e criadora é o ponto de onde parti e para onde retornei constantemente' (BERGSON, 1972, p.1148). 
vinculada a um corpo (matéria orgânica) que age no mundo, ou seja, é investigada a partir de suas manifestações mais concretas; por outro lado, há um aprofundamento do tratamento da duração, a qual passa a ser inseparável da memória e num certo sentido também da matéria.

Bergson parte da consideração dos corpos vivos como centros de ação e indeterminação, cuja consciência é proporcional ao seu grau de escolha e liberdade. Nesse sentido, a consciência é definida a partir da ação sobre a mátéria e não a partir do conhecimento ou de uma atitude contemplativa. Perceber conscientemente é primeiramente escolher, discernir uma parte no todo em função das exigências de ação do corpo vivo. Ora, se ser consciente é perceber e agir no mundo, e esse agir é indeterminado (supõe escolha), isso somente é possível graças a intervenção do passado. Pois, se os corpos vivos recebem excitações e as elaboram em 'reações imprevistas', essas reações não são 'escolhidas' ao acaso.

Essa escolha se inspira, sem dúvida nenhuma, em experiências passadas, e a reação não se faz sem um apelo à lembrança que situações análogas foram capazes de deixar atrás delas. Poderíamos dizer que não temos poder sobre o futuro sem uma perspectiva igual e correspondente sobre o passado [...] (BERGSON, 1999, p.68).

Ou seja, se por um lado a percepção, enquanto manifestação da consciência, não está separada da materialidade de um corpo, que age, por outro, por mais elementar que possa ser, ela implica sempre uma relação entre presente e passsado, ou, em outras palavras, a percepção consciente supõe memória. Aqui voltamos à noção de duração. E nesse ponto, a contribuição de Matéria e memória primeiramente vem salientar a ideia de conservação, ou seja, a duração não envolve apenas a ideia de sucessão ou passagem: ela é passagem e também conservação. Sem a conservação do passado seria impossível a continuidade de uma experiência psicológica, que supõe mudança, diferenciação qualitativa. Mas, se por um lado Bergson pretende afirmar a autonomia das lembranças em relação ao cérebro e mostrar que há uma conservação integral e em si de nosso passado ${ }^{2}$, por outro, nos chama a atenção para algo simples, mas crucial, isto é: 'toda percepção é já memória'.

$\mathrm{Na}$ fração de segundo que dura a mais curta percepção possível de luz, trilhões de vibrações surgiram, sendo que a primeira é separada da última por um intervalo enormemente dividido. Sua percepção, por mais instantânea que seja, consiste, portanto numa incalculável quantidade de elementos rememorados [...] (BERGSON, 1999, p.175-176).

Isto significa que a percepção, por mais elementar que possa ser, é

2 BERGSON, 1999, p.165-175. 
ainda percepção e já memória; de modo que nossa consciência presente, imediata e concreta 'consiste em grande parte no passado imediato'. Mais precisamente, ela é um ato temporal definido por Bergson como contração de instantes, que sempre expressa a relação entre presente e passado, e que por isso é testemunha de uma certa tensão de duração. Assim, se 'toda percepção já é memória', todo tipo de consciência opera uma determinada contração de instantes e se caracteriza por uma certa tensão de duração.

Bergson vai mais longe, e atribui à própria matéria uma determinada tensão, uma duração. Tendo definido o universo material como uma espécie de em si, que existe sem ser percebido, isto é, que nossa percepção não constitui, mas para o qual ela se abre, procura tirar algumas consequências dessa 'maneira de olhar a matéria', propondo, a partir da experiência do movimento, uma metafísica que a redefinirá em termos de duração.

Primeiramente, o universo material é então apresentado como uma continuidade movente. Mesmo que os hábitos e as necessidades de ação criem certas tendêncais que orientam nossa percepção a fragmentar uma continuidade primitivamente percebida em corpos individualizados, a consciência, em seus dados mais imediatos, representa a matéria como uma continuidade que muda como se girássemos um caleidoscópio (BERGSON, 1999, p.231). E não apenas a consciência imediata, mas também a ciência física confirma essa ideia. Bergson cita os físicos Faraday e Thomson: aos olhos de ambos, a solidez e inércia do átomo se dissolverão em movimentos ou em linhas de força: serão 'modificações, perturbações, mudanças de tensão ou de energia'.

Em ambas as hipóteses, vemos desvanecer-se, à medida que nos aproximamos dos últimos elementos da matéria, a descontinuidade que nossa percepção estabelecia em sua superfície. A análise psicológica nos revelava já que essa descontinuidade é relativa a nossas necessidades: toda filosofia da natureza acaba por considerá-la incompatível com as propriedades gerais da matéria (BERGSON, 1999, p.236).

Teoria científica e consciência, portanto, atestam a proposta de Bergson, que ao entrever ${ }^{3}$ um lado por onde abordar o problema da união entre a alma e o corpo ${ }^{4}$, aproxima sensações qualitativas e heterogêneas de um lado e movimentos quantitativos e homogêneos de outro ${ }^{5}$. É nesse contexto

\footnotetext{
${ }^{3}$ BERGSON, 1999, p.210.

4 Para Bergson, a 'obscuridade' desse problema clássico 'deve-se à dupla antítese que nosso entendimento estabelece entre 0 extenso e 0 inextenso, de um lado, a qualidade e a quantidade, de outro' (idem, p.211).

5 'À primeira vista, a distância parece intransponível. As qualidades são heterogêneas entre si, os movimentos homogêneos. As sensações, indivisíveis por essência, escapam à medida; os movimentos, sempre divisíveis, distinguem-sepor diferenças calculáveis de direção e de velocidade [...]. Mas a questão é justamente saber se os movimentos reais apresentam entre si apenas diferenças de
} 
que o movimento material (real e concreto) passa a possuir uma certa vibração interior, uma duração.

O movimento que a mecânica estuda é uma abstração ou um símbolo, uma medida comum, um denominador comum que permite comparar entre eles todos os movimentos reais; mas estes movimentos, considerados neles mesmos são indivisíveis que ocupam duração, supõem um antes e um depois, e religam os momentos sucessivos do tempo por um fio de qualidade variável que deve ter alguma analogia com a continuidade de nossa própria consciência (BERGSON, 1999, p.238).

Ou seja, o movimento material adquire uma determinada espessura de duração e, nesse sentido, deixa de ser visto apenas como um fenômeno interno, um 'fato de consciência': ele passa a ser também o movimento das qualidades fora de mim, nas coisas ${ }^{6}$. O mundo material será doravante pensado como um ritmo de duração muito particular, uma vibração mais relaxada e diluída, repartida em um número 'incalculável de momentos'. Em contato com nossa duração (concentrada e repartida em um número menor de momentos) esses momentos mais diluídos se contraem, passam a vibrar de modo diferente. 'Não podemos conceber, por exemplo, que a irredutibilidade de duas cores percebidas deve-se, sobretudo à estreita duração na qual se contraem trilhões de vibrações que elas executam em um de nossos instantes?' (BERGSON, 1999, p.238). Graças à nossa memória, somos capazes de contrair numa intuição única, de ritmo muito estreito e lento, os momentos de uma duração mais diluída do mundo material. Somos também responsáveis, por intemédio de nossa percepção, pelo aspecto subjetivo das qualidades sensíveis da matéria: condensamos suas mudanças sucessivas em uma certa tensão de duração.

Assim, a duração adquire um estatuto ontológico determinante à medida que toda realidade passa a ser concebida como um ritmo de duração, uma intensidade, uma tensão interior. $\mathrm{Na}$ realidade, afirma Bergson:

'não há um ritmo único da duração; é possível imaginar muitos ritmos diferentes, os quais, mais lentos ou mais rápidos, mediriam o grau de tensão ou de relaxamento das consciências, e deste modo fixariam seus respectivos lugares na série dos seres' (BERGSON, 1999, p.243).

Dentre essa pluralidade de durações, a nossa torna-se apenas uma duração de ritmo bem singular e determinado: ela contrai, num dado intervalo,

quantidade, ou se não seriam a própria qualidade, vibrando, por assim dizer, interiormente, e escandindo sua própria existência num número freqüentemente incalculável de momentos' (BERGSON, 1999, p.2378).

6 'O som difere absolutamente do silêncio, como também um som de outro som. Entre a luz e a obscuridade, cores, entre nunaces, a diferença é absoluta. A passagem de uma à outra é, igualmente, um fenômeno absolutamente real' (BERGSON, 1999, p.230). 
'um número limitado de fenômenos conscientes'. Bem diferente do tempo em geral, de que fala o físico. No espaço de um segundo, a luz vermelha, - aquela que possui o maior comprimento de onda e cujas vibrações são consequentemente as menos frequentes, - realiza 400 trilhões de vibrações sucessivas' (BERGSON, 1999, p.241). Ora, uma consciência que fosse capaz de perceber esses 400 trilhões de vibrações, cada uma separada da outra por dois milésimos de segundo, 'tempo necessário' para distingui-las, levaria mais de 25 mil anos para efetivar tal percepção. Ou seja, em si mesma, a sensação de luz vermelha que experimentamos durante um segundo, corresponde a uma sucessão que ocuparia 250 séculos (BERGSON, 1999, p.242). Em nossa duração, como destacávamos acima, um intervalo dado contém apenas um número restrito de fenômenos conscientes. Perceber não é senão 'imobilizar', condensar'. Condensamos em alguns segundos, 'períodos enormes de uma existência infinitamente diluída' e assim resumimos uma história muito longa. Nossa percepção opera uma descontinuidade num devir material, imobilizando-o (BERGSON, 1999, p.244). Por outro lado, se suprimimos esse 'ritmo particular' de duração - condição de nossa ação sobre as coisas - a essência do mundo material subsiste em sua continuidade, movendo-se ininterruptamente. Quer dizer, a temporalidade do universo material é irredutivel à nossa duração. Como Bergson mostrará em $A$ evolução criadora ao dar o exemplo do copo de água com açúcar: 'Se eu quiser preparar-me um copo de água com açúcar, por mais que faça, terei que esperar que o açúcar se dissolva' (BERGSON, 2005, p.10). Ora, esse tempo que tenho que esperar não é um tempo matemático, aquele que, como já apontamos, poderia continuar a ser aplicado ao mundo material, mesmo que este se desenvolvesse de um golpe no espaço; esse tempo 'coincide com minha impaciência, ou seja, uma certa porção de minha duração própria, que não pode ser prolongada ou encurtada à vontade. Não é mais algo pensado, mas algo vivido (...)' (BERGSON, 2005, p.10). Precisar esperar significa que um certo tempo interior precisa escoar, e que ele corresponde a todo o processo de dissolução do açúçar, e ainda, que esse processo dura, que ele precisa de um certo tempo para maturar. Compreendo-o pois sua duração é análoga à minha duração. Significa, na verdade, que 'o copo de água, o açúcar, e o processo de dissolução do açúcar' foram recortados do Todo pelos meus sentidos e meu entendimento interessados na ação, mas esse Todo é deles independente e progride ‘à maneira de uma consciência', isto é, ele dura ${ }^{7}$ (BERGSON, 2005, p.10-11). O

${ }^{7} \mathrm{O}$ objetivo da ciência é estabelecer um recorte no universo material para constituir sistemas isolados. Ela não considera as influências pelas quais esses objetos continuam submetidos (ou as considera num momento posterior). 'Essas influências são, todas, fios que ligam o sistema a outro sistema mais vasto, 
mundo material é comparado por Bergson a uma consciência cujos momentos se equilibram e se neutralizam, o grau mais baixo da duração. De modo que 'entre a matéria bruta e o espírito mais capaz de reflexão há todas as intensidades possíveis de memória', (BERGSON, 1999, p.261), ou seja, de duração.

Essa distinção entre durações de graus ou ritmos diferentes é a base para a constituição de uma ontologia geral e diversificada na filosofia de Bergson. Isto vai de encontro a um contexto muito particular na história das ciências, marcado pelo desenvolvimento das recém-nascidas ciências biológicas, sociológicas e psicológicas. Em uma comunicação à Sociedade Francesa de Filosofia, em 1901, intitulada O paralelismo psico-físico e a metafísica positiva, Bergson exalta o surgimento dessas ciências e destaca a necessidade de romper com o modelo da ciência matemática. Tendo sido de Platão a Descartes o modelo e o suporte da metafísica, a matemática foi até a véspera do século XIX a ciência mais solidamente constituída (BERGSON, 1972, p.490). No entanto, essas novas ciências representam um outro modelo para a metafísica: são ciências que se constituíram tendo por base uma experiência muito mais complexa que a experiência do tempo de Descartes, por exemplo. Ciências que surgiram da renúncia a uma matemática universal e que, por isso mesmo, 'observam e experimentam' sem a intenção de chegar a uma fórmula matemática, '(....) uma ciência mais flexível, instruída por uma experiência mais vasta e disposta a admitir nos fenômenos da natureza uma complexidade de organização dificilmente redutível ao mecanismo matemático' (BERGSON, 1972, p.474). Tendo-as como base, uma nova metafísica poderia recomeçar um esforço análogo ao das metafísicas modernas. A aliança entre metafísica e matemática trouxe como resultado a forma rígida das realidades metafísicas, 'incompatível com a fluidez da experiência', consequentemente, a experiência se tornou 'relativa' frente a um absoluto a ela transcendente; a aliança entre a metafísica e essas novas ciências, 'sem abandonar o fio da experiência', nos daria acesso a regiões da experiência que, demandando um esforço intelectual cada vez maior, nos encaminharia pouco a pouco para experiência absoluta (BERGSON, 1972, p.490). Esse esforço configuraria uma metafísica positiva, que se modelando aos fatos, não mais chegaria a conceitos rígidos e definitivos,

este a um terceiro que engloba a ambos e assim sucessivamente até chegarmos ao sistema o mais objetivamente isolado e o mais independente de todos, o sistema solar tomado como um todo. Mas, mesmo aqui, o isolamento não é absoluto. Nosso sol irradia calor e luz para além do planeta mais longínquo. $\mathrm{E}$, por outro lado, move-se arrastando os planetas e seus satélites, em uma direção determinada. $\mathrm{O}$ fio que o prende ao resto do universo é sem dúvida bastante tênue. No entanto, é por esse fio que se transmite até a menor parcela do mundo em que vivemos, a duração imanente ao todo do universo' (idem, p. 11). 
ao invés, elaboraria conceitos fluidos ${ }^{8} \operatorname{como}$ a própria realidade. Seria uma metafísica9 'saturada de experiência' (BERGSON, 1972, p.501). Assim, ao recomendar esse vínculo com as ciências ${ }^{10}$ de seu tempo Bergson indica que a metafísica futura, deverá levar em conta a nova configuração adquirida por nossa experiência: sobretudo, ela é complexa e diversificada: assim como não há 'uma ciência, mas ciências da natureza', não há 'um determinismo científico, mas determinismos científicos desigualmente rigorosos'. Ou seja, 'planos de experiência diferentes' (BERGSON, 1972, p.494).

Por tudo isso, a filosofia de Bergson não é uma metafísica ou 'filosofia da vida'. Trata-se antes de tudo de uma metafísica da duração; a duração aparecendo como um conceito flexível que engloba, num certo sentido, tudo. Desse modo, a realidade revela-se em si mesma diferenciada, e a metafísica vai justamente pensar a pluralidade de seus aspectos, que são, na

\footnotetext{
${ }^{8}$ Bergson é um crítico do conceito, mas não é um anti-intelectualista. Sua crítica incide sobre a conceitualização enquanto generalização e determinação abstrata da realidade. Como afirma em Introdução à metafísica, a simbolização conceitual de uma propriedade, por exemplo, ao conferir-lhe uma determinada extensão, a deforma, torna-a comum a uma infinidade de coisas. Mas a metafísica não pode dispensar os conceitos. Ou melhor, ela deve justamente se desvencilhar dos conceitos 'rígidos e já prontos' e criar novos: conceitos fluidos e flexíveis, suscetíveis de se moldar às sinuosidades da realidade (BERGSON,2006, p.194-195).

${ }^{9}$ Dois anos depois, o primeiro ensaio de Bergson sobre o método filosófico, Introdução à metafísica, vem completar essa comunicação ao fundar o método filosófico na intuição (termo diante do qual Bergson hesitou por muito tempo): esta será contraposta ao conhecimento por análise, conhecimento relativo, vinculado a 'pontos de vista', símbolos e conceitos. A intuição permitiria uma simpatia com o objeto, uma coincidência com o que ele tem de 'único' e 'inexprimível' (BERGSON, 2006, p.187). Para um aprofundamento do tema da intuição em Bergson, bem como de sua crítica ao conceito sugerimos a obra: Husson, Léon. L'intellectualisme de Bergson- Genèse et développement de la notion bergsonienne d'intuition. Paris: PUF, 1947.

${ }^{10}$ Essa recomendação é confirmada em Introdução à metafísica, e realizada por seu terceiro livro, $A$ evolução criadora, o qual se utiliza, desde as primeiras linhas, das aquisições da biologia. No primeiro desses textos Bergson insiste que esse vínculo com as ciências deve passar pela consideração do 'conjunto das observações e das experiências colhidas pela ciências positivas e, sobretudo, por uma reflexão do espírito sobre o espírito'. A intuição de uma realidade (com o que ela tem de mais interior) somente é obtida quando conquistamos uma 'confiança por meio de uma longa camaradagem com suas manifestações superficiais'. E nessa camaradagem é preciso não somente assimilar fatos marcantes, mas ainda acumular e fundir esses fatos, para que nos asseguremos de ter neutralizado as ideias preconcebidas e prematuras que os observadores 'sem o saberem' deixaram impregnadas em suas observações. Somente assim nos libertamos da 'materialidade bruta dos fatos conhecidos'. Para Bergson, 'o eclipse parcial' da metafísica ocorrido após a segunda metade do século XIX deve-se à 'extraordinária dificuldade' do filósofo em ter contato com uma ciência que se tornou cada vez mais 'diversificada'. A intuição metafísica, ainda que necessite dos conhecimentos materiais para se efetivar, não pode se caracterizar como um 'resumo ou síntese' desses conhecimentos. Ela 'distingue-se deles como a impulsão motora se distingue do caminho percorrido pelo móvel, como a tensão da mola se distingue dos movimentos visíveis no relógio. Nesse sentido, a metafísica nada tem em comum com uma generalização da experiência e, não obstante, poderia definir-se como a experiência integral' (BERGSON, 2006, p.233-234).
} 
verdade, graus de intensidade temporal: consciência, matéria e vida.

Mas o que Bergson quer dizer quando afirma, em seu terceiro livro, que a vida será considerada do ponto de vista psicológico? Vejamos. Em sua evolução, assinala, a vida não descreve uma trajetória única, como a de uma bala lançada por um canhão, mas tal como a de um obus que explode em fragmentos, e esses por sua vez também explodem em fragmentos que vão também explodir em fragmentos, e assim por diante. Tal como a fragmentação que se dá na explosão do obus, a fragmentação da vida em indivíduos e espécies possui duas causas: a resistência da matéria bruta e a força explosiva (no caso do obus, o metal, e a pólvora, respectivamente). Mas as causas mais profundas dessa fragmentação estão compreendidas no interior da própria vida, que é comparada a uma 'força explosiva' que traz em si um 'equilíbrio instável de tendências'. Um impulso, que em contato com a matéria é responsável pela diversidade das formas de vida. 'A vida é tendência e a essência de uma tendência é desenvolver-se em forma de feixe, criando, pelo simples fato de seu crescimento, direções divergentes entre as quais seu elã irá repartir-se' (BERGSON, 2005, p.109). Tal como nosso caráter, evolui por dissociações e bifurcações sucessivas e ao mesmo tempo deixando brotar de si as tendências nela contidas. No entanto, se somos forçados a escolher e abandonar 'personalidades' que, fundidas na infância, vão se tornando incompatíveis conforme nosso caráter se constitui, o mesmo não ocorre no domínio da vida: entre uma complexidade inicial, uma multiplicidade de elementos que se interpenetram, e o resultado final há uma continuidade, algo das origens é conservado. A vida 'conserva as diversas tendências que bifurcaram ao crescer. Cria, com elas, séries divergentes de espécies que evoluirão separadamente' (BERGSON, 2005, p.109). De modo que cada uma das direções divergentes conserva algo das outras, em cada uma delas encontramos 'lembranças virtuais' das outras: a vida humana (orientada pela inteligência), a dos insetos (orientada pelo instinto) e a dos vegetais (orientada pelo torpor insconsciente) são portanto complementares e jamais são encontradas em estado puro ${ }^{11}$.

No entanto, ao colocar o problema da relação entre vida e consciência Bergson indica que o movimento vital deve ser pensado como uma 'larga corrente de consciência' que penetrou a matéria ${ }^{12}$, 'carregada, como toda consciência, de uma multiplicidade enorme de virtualidades que se

11 'Embora a planta se distinga do animal pela fixidez e insensibilidade, movimento e consciência dormitam nela como lembranças que podem despertar. Aliás, ao lado dessas lembranças normalmente adormecidas, algumas há acordadas e atuantes. São aquelas cuja atividade não atrapalha 0 desenvolvimento da própria tendência elementar' (idem, p. 129).

12 'A vida, ou seja, a consciência lançada através da matéria [...]' (idem, p. 197). 
interpenetravam' (BERGSON, 2005, p.196). Nessa perspectiva, torpor vegetativo, instinto e inteligência não são somente o desenvolvimento de tendências inicialmente fundidas numa origem comum, mas também tornamse três reinos do mundo organizado originários de um imenso virtual, três modos pelos quais a consciência inscreveu-se na matéria. O que pode parecer paradoxal, é que entre eles há uma diferença real, uma diferença de natureza.

\begin{abstract}
O erro capital, aquele que, transmitindo-se desde Aristóteles, viciou a maioria das filosofias da natureza, é o de ver na vida vegetativa, na vida instintiva e na vida racional três graus sucessivos de uma mesma tendência que se desenvolve, enquanto são três direções divergentes de uma atividade que se cindiu ao crescer. A diferença entre elas não é uma diferença de intensidade, nem, de modo mais geral, de grau, mas de natureza (BERGSON, 2005, p.146-147).
\end{abstract}

Essa asserção de Bergson é crucial. Primeiramente, por sua insistência no fato de que a evolução se desenvolve de modo dissociativo e numa direção divergente de esforços. O processo evolutivo se dá em forma de feixe, como já foi dito, e assim 'afasta uns dos outros, ao longo de seu crescimento simultâneo, termos que inicialmente eram de tal modo complementares que se encontravam confundidos' (BERGSON, 2005, p.128). Por outro lado, como indica a citação acima, ele rechaça qualquer ideia que possa conferir uma superioridade da inteligência em relação ao instinto, por exemplo, podendo a primeira se sobrepor ao segundo. Inteligência e instinto 'se opõem e se completam', mas 'não são coisas da mesma ordem', não 'se sucederam uma à outra', e não são passíveis de hierarquização (BERGSON, 2005, p.147). O fato é que ambos conservam algo de uma origem comum, uma origem na qual se interpenetravam.

Bergson reitera em vários momentos, que a vida deve ser comparada a um elã, mas esclarece que trata-se apenas de uma imagem emprestada do mundo físico. Pois a vida, 'na verdade, é de ordem psicológica, e é da essência do psíquico envolver uma pluralidade confusa de termos que se interpenetram' (BERGSON, 2005, p.279). O que isto quer dizer? Significa que a vida não é unidade nem multiplicidade, tal como nossa consciência interior ${ }^{13}$. Uma

13 'Minha pessoa, num dado momento, é ela una ou múltipla? Se a declaro una, vozes interiores surgem e protestam, as das sensações, sentimentos, representações pelas quais minha individualidade se reparte. Mas se a faço distintamente múltipla, minha consciência insurge-se com a mesma força; afirma que minhas sensações, meus sentimentos, meus pensamentos são abstrações que opero sobre mim mesmo e que cada um de meus estados implica todos os outros. Sou, portanto - de um modo ou de outro, é preciso adotar a linguagem do entendimento, uma vez que apenas o entendimento tem uma linguagem - unidade múltipla e multiplicidade una; mas unidade e multiplicidade não são mais que vistas tomadas de minha personalidade por um entendimento que aponta para mim suas categorias: não entro nem numa nem na outra, nem nas duas ao mesmo tempo, ainda que as duas, reunidas, possam dar uma imitação aproximativa dessa interpenetração recíproca e dessa continuidade que encontro no fundo de mim mesmo. Assim é minha vida interior e assim é também a vida em geral' (idem, p.279-280). 
realidade que não se molda sobre o espaço ou entra nas categorias do entendimento ${ }^{14}$. Como dizíamos, a vida traz em si uma 'força explosiva', 'um equilibrio instável de tendências'. Isso significa que ela

$$
\begin{aligned}
& \text { é uma imensidão de virtualidade, uma mútua sobreposição de milhares e } \\
& \text { milhares de tendências que só serão no entanto 'milhares e milhares' uma vez } \\
& \text { exteriorizadas umas com relação às outras, isto é, espacializadas. O contato com } \\
& \text { a matéria decide a respeito dessa dissociação (idem, p.280). }
\end{aligned}
$$

Ou seja, essa força explosiva abriga em si mesma a diferença, sendo necessário apenas o obstáculo da matéria para essa diferença passar de virtual a atual. Sendo duração, a vida, como afirma Deleuze, 'é o que difere de si' (DELEUZE, 2012, p.127), ou ainda, 'é o processo da diferença' (DELEUZE, 2012, p.130). Trata-se de processo no qual uma virtualidade, ao dissorciar-se, realiza temporalmente as potências criativas que nela se interpenetravam. 'Diferenciar-se é o movimento de uma virtualidade que se atualiza' (DELEUZE, 2012, p.131). Esse movimento é duração, é progresso. Se há direções, no entanto não há um objetivo a ser atingido. Pois as direções são criadas 'ao mesmo tempo' que o ato que as percorre, não sendo senão a 'direção' desse ato (BERGSON, 2005, p.56). Nesse sentido, o movimento vital é criação. Uma evolução criadora. Tal o significado da vida como princípio psicológico.

A inteligência é o ponto culminante dessa evolução. Ela se constituiu ao longo da 'história da evolução da vida', por um movimento que progrediu ininterruptamente da linha que passa pelos vertebrados e desemboca no homem (idem, p. IX). Tornou-se a faculdade de ação e de conhecimento própria à espécie humana, faculdade que se adaptou perfeitamente à matéria inerte: de um lado, fabricando instrumentos para agir sobre a matéria, de outro, representando-se relações 'muito gerais' entre determinados objetos, em geral os sólidos. Asssim, promove a inserção de nosso corpo em seu meio. É com a matéria inerte ou o mundo inorganizado que a inteligência se sente 'à vontade', e sua definição é deduzida da noção de fabricação: ela é a 'faculdade de fabricar objetos artificiais, em particular utensilios para fažer utensílios, e variar indefinidamente sua fabricação' (idem, p.151). Ora, por todas essas características, a inteligência se torna incapaz de compreender a 'verdadeira natureza da vida', sua ação ou seu princípio, que é o próprio princípio da matéria. Criada pela vida, 'em circunstâncias determinadas para agir sobre coisas determinadas', ela não poderia abarcá-la: parte de um todo, não poderia a ele igualar-se; ademais, suas categorias são demasiadamente estreitas e rígidas para dar conta do vivo, na

${ }^{14}$ Nem a categoria do múltiplo, nem a do uno se aplicam perfeitamente à vida, ' nem a causalidade mecânica, nem a finalidade fornecem uma tradução suficiente do processo vital' (idem, p.193). 
maioria das vezes todos os seus quadros estouram (idem, p.X). Mas, o fato é que a 'filosofia evolucionista não hesita em estender às coisas da vida os procedimentos de aplicação que funcionam para a matéria bruta' (idem, p.XI). Essa afirmação, logo na introdução do livro, marca o reencontro de Bergson com o filósofo cujas ideias sobre o tempo criticou, e que de certo modo impulsionou o início de sua ontologia da duração, ou seja, Spencer. Nesse momento, após um percurso começado no Ensaio, e a progressiva construção de uma ontologia e de um método, que inclusive é justificado e realizado por esse seu último livro, nosso filósofo fala com propriedade do 'falso evolucionismo' de Spencer, contraposto agora ao seu 'verdadeiro evolucionismo’. A última seção do último capítulo do livro, não por acaso, é dedicada a Spencer: Bergson finaliza seu terceiro livro, ápice de uma trajetória, acertando as contas com aquele cuja filosofia o fez constatar o quanto a duração, ou o tempo real, nunca foram verdadeiramente considerados pelos sistemas filosóficos tradicionais. Não pretendemos nos debruçar diretamente sobre a crítica de Bergson à filosofia da natureza de Spencer; nossa intenção, antes de finalizar, é primeiramente situar a problemática em torno do conhecimento da vida e dos poderes ilimitados da inteligência, e depois indicar como suas análises críticas desembocam na proposição de uma experiência intuitiva (consciente) de nós mesmos enquanto totalidade individual. Por fim, tentaremos tirar alguma conclusão sobre a legitimidade desse projeto filosófico que procura especular em sua profundidade a natureza da consciência, da matéria e da vida.

Bergson critica uma determinada filosofia da natureza por esta não compreender a especificidade da inteligência e de seu objeto, e tratar o ser vivo com os mesmos procedimentos que trata a matéria inerte.

Começara por nos mostrar na inteligência um efeito local da evolução, uma
pequena luz, talvez acidental, que ilumina o vai-e-vem dos seres vivos na estreita
passagem franqueada à sua ação: e eis que, de repente, esquecendo o que acaba
de nos dizer, transforma essa lanterna manobrada no fundo de um subterrâneo
em um Sol que iluminaria o mundo. Intrepidamente, apenas com as forças do
pensamento conceitual, lança-se na reconstrução ideal de todas as coisas, até
mesmo da vida (idem, p.XI).

Mas, essa filosofia, ao ver-se conduzida a dificuldades e contradições, 'rapidamente renuncia à sua ambição primeira': a inteligência é declarada incapaz de reconstruir a própria realidade, podendo somente 'recompor' sua imitação ou sua imagem simbólica; consequentemente, não pode conhecer a essência das coisas, ou seja, o absoluto lhe é incognoscível ${ }^{15}$ (ibidem). Ora, para

${ }^{15}$ Além de Kant, Spencer é visado nessa crítica: incognoscivel é o nome que este último atribui ao absoluto. 
Bergson, se a inteligência está voltada essencialmente para a ação sobre a matéria inerte, sua ação não pode 'mover-se no irreal'. Ela deve nos oferecer algo da própria essência da matéria, um absoluto da matéria ${ }^{16}$. Ademais, seus quadros gerais não possuem nada de inexplicável ou irredutível, pois são relativos às necessidades da ação. A inteligência não é uma faculdade destinada à especulação pura: ao concebê-la com tal destinação, não conseguimos explicar suas categorias e acabamos tomando-as por uma espécie de absoluto.

O entendimento teria caído do céu com sua forma, como nascemos todos com
nosso rosto. Definimos essa forma, sem dúvida, mas é tudo que se pode fazer, e
não há que procurar por que ela é aquilo que ela é em vez de qualquer outra
coisa. Assim, sentenciaremos que a inteligência é essencialmente unificação, que
todas as suas operações têm por alvo comum introduzir uma certa unidade na
diversidade dos fenômenos, etc (idem, p.165).

Bergson indaga se o termo 'unificação' não seria um termo vago e menos claro que o termo 'relação' ou 'pensamento'. Por que ela teria querido unir? Por simplesmente precisar da unificação? Se assim foi, nosso conhecimento tornou-se dependente de determinadas exigências do espírito; ora, mas se essas exigências fossem outras? Por não estar suspensa a nada, tudo tornou-se suspenso a inteligência (ibidem). E nos servimos dela como da vista para abarcar o horizonte (idem, p.208). Ora, junto, e talvez mais forte que essa concepção da inteligência, encontra-se, na maior parte dos filósofos ${ }^{17}$, a crença na unidade da natureza. Para eles, não há uma demarcação entre o organizado e o inorganizado.

Uns falam do inorgânico e pretendem, ao complicá-lo consigo mesmo, reconstituir o vivo; os outros põem primeiro a vida e encaminham-se para a matéria bruta por um decrescendo habilmente arranjado; mas, para uns e para outros, na natureza há apenas diferenças de grau - graus de complexidade ${ }^{18}$ na primeira hipótese, graus de intensidade ${ }^{19}$ na segunda. Uma vez esse princípio admitido, a inteligência torna-se tão vasta quanto o real (...) (idem, p.207-8).

Os postulados implícitos a essas especulações são: a natureza é una e a inteligência abarca-a por inteiro. O que pressupõe que nosso conhecimento é coextensivo à experiência em sua totalidade: a inteligência é dada ao mesmo tempo que a realidade que a compreende, tornando-se assim um espelho da natureza. Nenhuma dessas especulações se propõe compreender a gênese da

\footnotetext{
16 'Se a forma intelectual do ser vivo se modelou pouco a pouco pelas ações e reações recíprocas de determinados corpos e de seu entorno material, como se furtaria a nos oferecer algo da essência mesma da qual os corpos são feitos? A ação não poderia mover-se no irreal' (ibidem, p. XI). Cf. (ibidem, p.216).

${ }^{17}$ Bergson cita Fichte e Spencer além de, certamente, visar Kant.

${ }^{18}$ Spencer.

${ }^{19}$ Fichte.
} 
inteligência. Como já colocamos, a inteligência está essencialmente vinculada à ação. Mas ela é o produto de um esforço da vida, ou melhor, um dos modos de ação escolhidos pela vida: modo de ação mediato na qual ela fabrica seu instrumento moldando a matéria inorgânica (idem, p.154). Nesse sentido, seu conhecimento é apenas uma parte da realidade.

Para Bergson, é preciso vincular a inteligência à totalidade da vida, ou, mais precisamente, reinseri-la no movimento total da vida, numa espécie de retorno ao seu movimento imanente ${ }^{20}$. De modo que a inteligência abandone seus instrumentos e percorra um caminho para fora dela, invertendo sua direção natural. A filosofia nesse sentido se caracterizaria pelo 'esforço para fundir-se novamente no todo' (idem, p.209). Seria uma filosofia do todo e não da inteligência. Por outro lado, ao mesmo tempo que reapreender o movimento total da vida, a filosofia deve intervir no território dos fatos e não abandonar à ciência a consideração destes. Se ela não intervém, está condenada a receber os fatos e as leis tais como o cientista lhe os transmite. Os fatos e o julgamento dos fatos caminham juntos, segundo Bergson: na natureza, 'as leis são interiores aos fatos' (idem, p.212-213); assim, as descrições e as análises dos fatos que o filósofo receberá da ciência já estarão comprometidos com o modo pelo qual a ciência concebe a realidade. Ora, a 'ciência positiva é obra de pura inteligência', e a inteligência, 'afinada' com a matéria inorganizada e geometrizada trata tudo como inerte. Necessariamente, a ciência, ao tratar o vivo, trata-o como trata os fatos fisicos. O papel da filosofia seria então o de 'examinar o vivo sem segundas intenções de utilização prática, libertando-se das formas e dos hábitos propriamente intelectuais' (idem, p.214). Adotando a perspectiva da ciência positiva, ou seja, abandonando a ela os fatos biológicos e psicológicos, a filosofia acabará por impor à natureza uma visão mecanicista e, concomitantemente, uma unidade abstrata.

A filosofia deve então começar por estabelecer uma distinção entre o inerte e o vivo; assim procedendo, considera o vivo com os olhos que não são os da ciência positiva e invade o domínio da experiência para de certo modo desfazer a visão científica do mundo: essa distinção mostraria primeiramente que, se a inteligência é essencialmente voltada para ação útil sobre a matéria inerte, esta ação não cria ficções e nos entrega um absoluto, algo da essência da matéria; por outro lado, ela esclareceria também que, ao voltar-se para o vivo, a ciência não obterá dele o mesmo domínio que obtém sobre a matéria bruta, pois, como o vivo não se insere completamente nos quadros da física, este conhecimento será simbólico e vinculado às contingências da ação. Nesse ponto, ao conhecimento científico deveria ser acrescentado o conhecimento

${ }^{20}$ Cf. p.50-51; 54-55; 192. 
metafísico ${ }^{21}$. O desenvolvimento combinado e progressivo dos dois ${ }^{22}$, elevaria nosso conhecimento da realidade, o qual, mesmo incompleto, nos proporcionaria um absoluto 23 .

Essas análises culminam com o anúncio da possibilidade do encontro de uma 'unidade verdadeira, interior e viva' da natureza, a partir da renúncia à unidade abstrata imposta pelo entendimento e da inversão da direção natural do conhecimento parcial da inteligência. Ora, o surpreendente é que essa unidade somente pode ser encontrada se partirmos de nossa vida, de um esforço intuitivo para transcender a inteligência pura, em direção ao que temos de mais interior. Ou seja, em direção à duração. Esse esforço consciente sobre nós mesmos é um esforço de tensão, ou, mais precisamente, de 'contração de nossa personalidade sobre si mesma', no qual apanhamos 'nosso passado que se esquiva, para empurrá-lo, compacto e indiviso, em um presente que ele irá criar ao nele se introduzir'. Ora, esse esforço temporal em busca de uma unidade, mesmo admitindo graus, pois 'nunca nos temos por inteiro', pode nos conduzir à liberdade: esses momentos raros de coincidência interior coincidem com nossas ações livres. E quanto mais profundo nosso sentimento da duração, quanto maior nossa concentração, mais nos inserimos numa realidade, ou, nas palavras de Bergson, numa 'vida' que absorve a intelectualidade, superando-a' (idem, p.218). Pois justamente, a inteligência não comprende o novo estado, ou as novas configurações internas proporcionadas por essa concentração que faz nosso passado se introduzir no presente para nele fazer brotar o novo.

Mas, ao interrompermos esse esforço que 'empurra no presente a maior parte possível do passado' nossa consciência pode realizar um outro movimento intuitivo, ela pode distender-se numa direção oposta à primeira, ou seja, num movimento de exteriorização, no qual cessamos de agir e nosso eu se dispersa em sensações ou em lembranças. Esse movimento jamais é completo, pois haverá sempre um resquício de memória e vontade, no entanto, segundo Bergson, é possível 'entrever', no limite, 'uma existência feita de um presente que recomeçaria incessantemente 24 , um instantâneo que se reitera

${ }^{21}$ Ou seja, o conhecimento que pretende 'possuir uma realidade absolutamente' e não 'conhecê-la relativamente', 'se colocar nela, ao invés de adotar pontos de vista sobre ela, de ter dela a intuição, ao invés de fazer sua análise, enfim, de apreendê-la fora de toda expressão, tradução ou representação simbólica, a metafísica é exatamente isso'. (BERGSON, 2006, p.188).

22 É também destacável o que Bergson afirma em $O$ pensamento e o movente: 'Em suma, queremos uma diferença de método, não admitimos uma diferença de valor entre a metafísica e a ciência' (BERGSON, 2006, p.45).

${ }_{23}$ 'No absoluto somos, circulamos e vivemos' (BERGSON, 2005, p.217).

24 Trata-se da matéria, desde Matéria e memória definida nesses termos (BERGSON, 1999, p.154 e 236). 
indefinidamente. Mas, do ponto de vista da duração, essa existência produz abalos quase desvanescentes, mas não nulos. Esta seria a existência física, e a primeira, a existência psíquica (idem, p.219).

Essas existências, concebidas por analogia ${ }^{25}$ ao duplo movimento interno a nossa consciência, são movimentos ou processos originais de direção oposta: de um lado a 'espiritualidade', movimento de concentração, de outro a 'materialidade' e a intelectualidade, movimento de exteriorização e inverso ${ }^{26}$ ao primeiro. Trata-se de processos inversos de uma mesma realidade que é mobilidade, ou seja, duração. $O$ físico, nesse sentido, não é senão o psíquico invertido. Bergson, nesse ponto, esclarece que a matéria é um movimento de nossa consciência, um movimento possível desta; por isso, ela é mais extensa do que espacial: é a continuação, pela inteligência, desse movimento de distensão que faz surgir o espaço (como um esquema) e a geometria. A matéria não é constituída por partes exteriores umas às outras ${ }^{27}$, ela é, propriamente, uma tendência $a^{28}$ em direção ao espaço: 'a matéria se estende no espaço sem estar nele absolutamente estendida'. Ao representá-la como divisível,

decomponível em sistemas isolados, ao lhe atribuir elementos bem distintos que mudam uns com relação aos outros sem mudarem eles próprios (...), ao the confererir, enfim, as propriedades do espaço puro, nós nos transportamos ao termo do movimento do qual ela simplesmente desenha a direção (BERGSON, 2005, p.222) ${ }^{29}$.

A inteligência se coloca no termo desse processo através da representação do espaço puro como um termo ideal, um limite no qual o movimento de distensão culminaria ${ }^{30}$. Ou seja, a inteligência compreende a matéria através do espaço. A inversão do primeiro movimento, o da espiritualidade, dá então origem a representação de uma matéria mais espacial do que ela realmente é.

Quais os ensinamentos que podemos extrair dessas páginas difíceis

25 Esse procedimento metafísico é muito bem comentado por WORMS, 2011, p.248: 'deve haver intuição, isto é, consciência, não diretamente de alguma coisa que nos supera e da unidade da vida ou do mundo em geral, mas de alguma coisa em nós que nos define, permitindo conceber por analogia a unidade da vida e do mundo'.

${ }^{26}$ Mais adiante, Bergson define esses movimentos como duas 'ordens' e utiliza o termo interrupção ao invés de inversão: a interrupção do movimento vital ou espiritual daria origem ao movimento material, tal como uma inversão; nesse sentido não haveria desordem (BERGSON, 2005, p.228-257).

${ }^{27} \mathrm{Ou}$ seja, partes completa e reciprocamente independentes. 'Não há ponto material que não aja sobre todo outro ponto material' (BERGSON, 2005, p.221).

${ }^{28}$ Grifo nosso.

${ }^{29}$ Um excelente comentário sobre a diferença entre matéria, extensão e espaço é apresentado por CANGUILHEM, 2007, p.146-148.

30 O espaço é uma representação abstrata, um esquema (no qual vigora a pura exterioridade), construído pela inteligência. 
do terceiro capítulo de $A$ evolução criadora? Como vimos, o problema acerca do conhecimento da vida, ou melhor, o problema dos limites de nosso conhecimento intelectual conduziu nosso filósofo a um questionamento acerca da unidade concreta da natureza. Mas como e onde encontrar uma unidade que supera o conhecimento parcial e distinto da inteligência? Bergson propõe uma inversão radical da direção natural de nossa inteligência. Essa inversão passa pelo ato metafísico por excelência, ou seja, pela intuição daquilo que temos de mais interior, de nossa própria unidade individual e pessoal, ou seja, em nós mesmos encontramos uma unidade viva; mas não apenas isso, podemos ainda, num movimento intuitivo inverso ao primeiro, numa direção oposta à de nossa interioridade, apreender a exteriorização e a justaposição de nossas sensações e lembranças, numa ordem exterior a nós. E tudo se passa como se essa experiência consciente sugerisse $3^{31}$ ao filósofo a existência, na realidade, de dois movimentos originiais, um de tensão (liberdade), outro de extensão (necessidade mecânica), e que fosse possível a passagem de um a outro invertendo o sentido desses movimentos (BERGSON, 2005, p.257). Ora, o que legitima essa sugestão $0^{32}$ que estabelece uma analogia entre consciência individual e realidade? Bergson oferece uma resposta a essa pergunta na conferência $A$ intuição filosófica (1911), num momento em que indaga se a consciência, ao sondar sua 'própria profundidade', mergulha 'mais fundo no interior da matéria, da vida, da realidade em geral'. Imediatamente assevera que tal afirmação seria contestável se, de um lado, a consciência fosse um epifenômeno da matéria; e, de outro, se a consciência humana, mesmo 'aparentada a uma consciência mais alta e mais vasta', fosse pura transcendência:'Mas não! A matéria e a vida que preenchem o mundo estão igualmente em nós; as forças que trabalham em todas as coisas, sentimo-las em nós; seja lá qual for a essência íntima daquilo que é e daquilo que se faz, somos parte disso' (BERGSON, 2006, p.143). Ou seja, em nós, temos a experiência da matéria e da vida.

Assim, é graças ao pensamento do ser como duração que a filosofia da natureza de Bergson pode consagrar-se como um esforço para englobar não apenas as diferenças entre consciência, matéria e vida, mas sobretudo articulálas numa relação que se dá sempre através da intuição.

${ }^{31}$ Grifo nosso.

${ }^{32}$ Grifo nosso. 


\section{Referências Bibliográficas}

BERGSON, H. Mélanges. Textes publiés et annotés par André Robinet. Paris: PUF, 1972.

. Essai sur les données immédiates de la conscience. Édition critique, PUF, Paris, 2007. . Matéria e memória. São Paulo: Martins fontes, 1999. - A evolução criadora. São Paulo: Martins fontes, 2005. . O pensamento e o movente. São Paulo: Martins fontes, 2006. . L'évolution créatrice. Édition critique, PUF, Paris, 2009.

CANGUILHEM, G. "Commentaire au troisième chapitre de L'évolution créatrice". In: WORMS, F. (Org.). Annales bergsoniennes III: Bergson et la science. Paris: PUF, 2007.

DELEUZE, G. "A concepção da diferença em Bergson”. In: O Bergsonismo. São Paulo: Editora 34, p.119-148, 2012.

MONTEBELLO, Pierre. L'autre métaphysique. Paris: Desclée de Brouwer, 2003.

. "Différences de nature et différences de la nature". In: Vieillard Baron, J.-L. (Org.). Bergson, la durée et la nature. Paris: PUF, p.137-158, 2004.

PRADO JÚNIOR, Bento. "Presença e Campo Transcendental - Consciência e Negatividade na Filosofia de Bergson. São Paulo: EDUSP, 1989.

WORMS, Frédéric. Le vocabulaire de Bergson. Paris: Ellipses, 2000. . "A concepção bergsoniana de tempo". In: Dois Pontos, (Revista dos Departamentos de filosofia da Universidade Federal do Paraná e da Universidade Federal de São Carlos), vol. I, n.1, 2004, p.129-149. . Bergson ou os dois sentidos da vida. São Paulo: Unifesp, 2011. 